Article

\title{
Innovators in Urban China: Makerspaces and Marginality with Impact
}

\author{
Monique Bolli \\ Institute for Area and Global Studies, College of Humanities, EPFL-Ecole Polytechnique Fédérale de Lausanne, \\ 1015 Lausanne, Switzerland; E-Mails: monique.bolli@epfl.ch, moniquebolli@gmail.com
}

Submitted: 30 April 2020 | Accepted: 19 June 2020 | Published: 14 October 2020

\begin{abstract}
In China, the emergence of makerspaces, hackerspaces, Fab Labs, and innovation labs reflects top-down and bottom-up dynamics. The grassroots movements and governmental efforts promoting innovation and creativity are part of the maker trend linked to the rise of the Internet and access to digital tools. The urban imaginary of the maker culture creates networks and events both globally and locally. The first makerspaces opened in Shanghai and Shenzhen in 2010 and attracted the attention of the government, which published an initiative in 2015 that influenced the typology of makerspaces in China. The ephemeral spaces for innovators, hackers, makers, and entrepreneurs shaped by this cultural context and local ecosystem are urban phenomena investigated with social anthropological and experimental methodologies to better understand the extension and platformisation of these autonomous and co-opted communities and narratives. This research fills the knowledge gap on makerspaces in China in recent years, showing the impact of governmental initiatives on a grassroots culture, the possible roles of makers, and the complexity and unlimitedness of the maker culture through international partnerships for projects such as Designed in Ethiopia and Kabakoo Academies.
\end{abstract}

\section{Keywords}

Africa; change-makers; changing narratives; China; empowerment; innovation; makerspaces

Issue

This article is part of the issue "The City of Digital Social Innovators" edited by Chiara Certomà (Ghent University, Belgium), Antonella Passani (T6-Ecosystems, Italy) and Mark Dyer (University of Waikato, New Zealand).

(C) 2020 by the author; licensee Cogitatio (Lisbon, Portugal). This article is licensed under a Creative Commons Attribution 4.0 International License (CC BY).

\section{Introduction}

The last few years have seen a proliferation of numerous types of makerspaces, hackerspaces, Fab Labs, coworking spaces, accelerators, and incubators (Troxler \& maxigas, 2014), all of which bring alternatives to wellestablished infrastructures, generating new dynamics. Not only do they introduce a new idea to the structure of work and hobby (Wen, 2017, p. 7), they also blur the lines between professional and private activities. Dual categories such as public/private, individual/collective and offline/online, are to be rethought as they are generally limited by their boundaries, and do not represent the hybrid liminal spaces that makerspaces offer. 'Makerspace' is a concept uniting many types of spaces and activities under one umbrella where all kinds of profiles (objectives, languages, and skills) are mixed. The rhizomic (Deleuze \& Guattari, 1987) characteristic of the maker culture is in- spirational and affects makerspaces (places, people and politics), urban fabric (urban integration, empowerment, ecosystems and identities), and outreach (projects without borders, partnerships and business).

Manual work is not novel, but the revival of this making, do-it-yourself (DIY), tinkering and tech enthusiasm, and trend, make it more palpable. According to A. Smith, globally, the process of democratising innovation also takes place with makerspaces, they are: "[A] site of struggle over profound issues material to social futures, and hence an example of innovation democracy in action" (Smith, 2017, p. 14). But also, innovation needs support from peers, groups or networks as Akrich, Callon, Latour, and Monaghan (2002) write: "Innovation is perpetually in search of allies. It must integrate itself into a network of actors who take it up, support it, diffuse it" (pp. 203-204). Makerspaces are 'social innovation niches' (Pel \& Kemp, 2020) beyond products, con- 
nections between people and partnerships are the key. Indeed, makerspaces are empowering members of communities and their networks (Shorthose, 2004).

Urban farming, drone evenings, plastic recycling, robot competitions, watchmaking, kids' lamps, laser-cut masks, cup printing and painting, silk screening, prototyping for one's projects or external mandates are part of the activities of makerspaces in Shanghai and Shenzhen where fieldwork was conducted. This article is based on a four-year social anthropological research (2016-2019) with intensive fieldwork and over 50 interviews mainly in the Shanghai and Shenzhen maker environments. The classical social anthropological methodology is completed by experimental multidisciplinary workshops with expert and public participants exchanging knowledge and making (methodology, maps, zines) together (Bolli, Renaud, Bloch, \& Protti, 2020). Surpassing classic research methodologies and creating multi-sited, fast-changing and multi-layered narratives of research is important and challenging (Driessen \& Jansen, 2013; Holmes \& Marcus, 2008; Pink, 2015). Based on interviews, Chinese governmental websites, makerspaces' social media and academic publications, I show how urban social innovators influence or are influenced by their environment. The Chinese government's turn towards innovation has changed the path and typology of makerspaces in China without creating a revolutionary elite or erasing the existing grassroots culture. Makerspaces have an impact on personal lifepaths and globally connected projects; they have been praised (Lindtner \& Li, 2012) and their instrumentalisation underlined (Wang, 2016) and criticised (Shea \& Gu, 2018). Showing their path, complexity and narratives in the context of urban China gives a voice to makers and fills the knowledge gap, showing their potential for impact.

Here, to contextualise the topic I first present the 'makers in China' showing a timeline of this young phenomenon and discussing the complexity of interpretations of concepts and translations, specifically for chuangke (创客) part of 'maker' (创客人) and 'makerspace' (创客空间). I then discuss the typologies of spaces and places developed in the framework of this field-oriented research before coming back to its core, the role of the makers. I then turn to the Chinese urban narratives before opening up the topic to the outreach of social innovators in urban China.

\section{Makers in China}

The global maker culture, linked to the concept of DIY (Day, 2016; Gibb, 2015; Huang, 2017), has experienced an explosive success with the growing access to the Internet, therefore facilitating the knowledge exchange, personal fabrication, and access to tools (Anderson, 2012). This narrative connects hobbyists and entrepreneurs enthusiastic of manual work. The maker culture in China is young, experimental and ephemeral. In China, the first makerspaces appeared in 2010-2011 with XinCheJian in Shanghai, Chaihuo in Shenzhen, and Beijing makerspace in Beijing. The three spaces still exist but have changed, shaped by the "boom and bust of makerspaces" (Xue, 2018). Maintaining a community and minimal financial stability are both key challenges. The non-profit business models are endangering the survival of makerspaces in terms of sustainability. Yet, these collaborative spaces, combining individualistic and shared projects, in a non-hierarchical organisation, caught the government's attention. As innovation enablers, first on a local and, if successful, on a global level, makerspaces were perceived as having the potential of supporting a changing economy and creating successful entrepreneurs.

\subsection{A Young Fringe Phenomena}

Considered as a 'fringe phenomena' (Troxler \& maxigas, 2014), the rather marginal maker culture inscribes itself in a 'maker culture imaginary' (Shea \& Gu, 2018, p. 54) where narratives shape concepts and places. The maker culture which I write about started growing in China step by step with different actors. Following the opening of the first makerspaces, the annual public maker activities commenced with carnivals and fairs in 2012 as shown in Figure 1 . In the continuity of the first makerspaces, more opened in 2013 and 2014. In 2015, the Chinese government positioned itself by promoting the chuangke maker-entrepreneurship initiative (Marshall \& Rossi, 2017) and launching officially supported events resulting in the spread of the maker culture in China that climaxed in 2015-2016 with thousands of spaces in the country according to a news channel relaying a piece of Chinese governmental information ("China has ranked first," 2017). While some data write about thousands ("China has ranked first," 2017; Xue, 2018), others reveal around 100 active spaces at the mentioned peak (Kingsley \& Saunders, 2016). The dichotomies between these references are not research-limiting, providing an opportunity to showcase discrepancies of the maker culture narratives. The definition of the makerspace does vary: is it the number of autonomous communities prone to experimentation (hobbyists/freelancers), the professional quasi-incubators, or the companies with a makerspace in their offices?

The Chinese government's interest has encouraged makerspaces pushing for a transformation and a reinterpretation of the trend: "The government's initiative has, in the long run, reduced the number of makers as it has transformed the idea of maker into entrepreneur" (Xue, 2018). Despite the peak in the number of makerspaces reached shortly after the 2015 governmental experimental initiative, the maker culture, revitalising and restoring hands-on work, is marginal as it counts a few spaces in each city which remain in the experimentation that does not purely aim at incubating new products. Such marginality, here in the sense of rarity and in opposition to the narrative of the booming move- 


\begin{tabular}{|c|c|c|c|c|c|c|}
\hline $\begin{array}{r}\text { 2010-1 } \\
1^{\text {st }} \text { makerspaces } \\
\text { Xinchejian (Shangh } \\
\text { (Shenzhen), Beijing } \\
\text { hobbyist/co-wor }\end{array}$ & $\begin{array}{l}1 \\
\text { in China } \\
\text { ai), Chaihuo } \\
\text { makerspace } \\
\text { king type }\end{array}$ & $\begin{array}{r}2 \\
1^{\text {st }} \mathrm{F} \\
\text { Fab Lat } \\
\text { Universit } \\
\text { educat }\end{array}$ & $\begin{array}{l}013 \\
\text { ab Lab } \\
0 \text { (Tongji } \\
\text { y, Shanghai) } \\
\text { ional type }\end{array}$ & $\begin{array}{r}\text { Hybrid } \\
\text { SZOIL (Sh } \\
\text { (Shanghai } \\
\text { Entreprene }\end{array}$ & $\begin{array}{l}\text { 2015-16-17 } \\
\text { makerspaces open } \\
\text { enzhen), innomaker+ } \\
\text { x.factory (Shenzhen), } \\
\text { urial / platformized type }\end{array}$ & Continuous \\
\hline $\begin{array}{l}\text { 1990s maker culture starts } \\
\text { Europe / USA (Moilanen 2012) } \\
\text { 2000s ecosystem changes in } \\
\text { China: economic reforms, } \\
\text { sharing economy } \\
\text { (Renaud et al. 2017) }\end{array}$ & $\begin{array}{r}201 \\
\text { First maker } \\
\text { and maker } \\
\text { Shanghai, S } \\
\text { and Be }\end{array}$ & $\begin{array}{l}2 \\
\text { carnivals } \\
\text { faires in } \\
\text { henzhen } \\
\text { ijing }\end{array}$ & $\begin{array}{r}2014 \\
\text { Political er } \\
\text { Chuangke is } \\
1^{\text {st }} \text { Natior } \\
\text { Entreprene } \\
\text { Innovatic }\end{array}$ & $\begin{array}{l}\text { 4-15 } \\
\text { nthusiasm } \\
\text { is redefined } \\
\text { nal Mass } \\
\text { eurship and } \\
\text { on Week }\end{array}$ & $\begin{array}{r}\text { 2017-18 } \\
\text { Belt and Road Summi } \\
\text { Maker Cooperation (2 } \\
\text { Belt and Road Internat } \\
\text { Maker Forum (201 } \\
\text { (both with Ethiopian sp }\end{array}$ & $\begin{array}{l}\text { for } \\
\text { 17) } \\
\text { nal } \\
\text { kers) }\end{array}$ \\
\hline
\end{tabular}

Figure 1. Makers in China timeline. Source: Bolli (2020).

ment "nurturing the next wave of Chinese innovators" (Ma, 2015), represents freedom of experimentation for those involved. The risk of institutionalising ephemeral structures of change is to not allow their natural evolution and failure opportunities by pushing entrepreneurship. It is a new type of culture, which keeps adapting.

The specificity of makers in China is that the government recognised the potential of makerspaces fitting in a changing ecosystem and representing a possible drive towards economic success, but for a short moment only. The translation and co-optation of the maker culture in China has created multi-faceted types of makerspaces born from bottom-up and top-down dynamics. After the governmental enthusiasm expressed, different trends have emerged, such as professional-oriented makerspaces accepting only already skilled makers as x.factory Shenzhen or innomaker+ in Shanghai, or platformised makerspaces collaborating online and welcoming teams or projects from anywhere in the world as the Shenzhen Open Innovation Lab (SZOIL) and x.factory in Shenzhen, and which have widened the types and possibilities of partnerships. Rather than replacing one typology for another, the typology of makerspaces continues to diversify with trends and community interests. This official accent on entrepreneurship is what differentiates the maker culture in China from other countries (Wen, 2017). In 2017-2018, several grassroots projects kept growing between the Shenzhen entrepreneurial and platformised makerspaces and makers in African countries (see examples in section 5.2).

\subsection{Definition of Chuangke and the 'Lost in Translation' Effect}

What all makers share is an attraction for self-making or self-accomplishment. Doing is of great value. The 'homo faber' (Lallement, 2015) resuscitated by hobby, the craftsman turned 'outward' by craftwork, where the "value of experience [is] understood as craft" (Sennett, 2009, p. 288), the "people who regard technology as an invitation to explore and experiment of, with the most inclusive possible definition of technology, meaning any skill or technique that we learn and employ" (Dougherty \& Conrad, 2016, p. xv), or as cited by Wang: The ones "devoted to innovation passionately" and "who control the production tools themselves" (Yu \& Deng, 2015, p. 46), or the ones who are going to realise the collective dream of the Chinese nation (Keane \& Chen, 2017; Lin \& de Kloet, 2019).

If the maker culture is global, translating its vocabulary adds dimensions that need to be taken into account. While the term maker as used in English is very wide and includes anyone from those who tinker to engineers, the Chinese term is more precise. Chuangke ren (创客人; maker), and chuangke kongjian (创客空间; makerspace) have developed from an open concept to referring specifically to entrepreneurs or freelancers who start their own business or develop innovative ideas. Chuangke (创客) is composed of two characters, namely, chuang (创; start something or achieve) and ke (客; guest or visitor), the first is for example also used in chuangxin (创新; to innovate, innovation) including the character xin (新; new, fresh; see Bolli, 2020; Renaud, Graezer Bideau, Bolli, \& Laperrouza, 2017). Even though the term chuangke is not always translated and used in mandarin Chinese, it is essential in the shaping of the Chinese maker culture. Not only are spaces influencing definitions, the definitions are also translated into ideologies of spaces that have been spreading worldwide. The positive connotations of chuangke in Chinese serve a precise purpose as they are "employed in positive terms in political and public discourse as a way to foster social change and technological innovation" (Lindtner, Hertz, \& Dourish, 2014). Chuangke was chosen to define makers for its positive connotation but is now not only used for makers but also for entrepreneurs or businesswomen/men. Even if the chuangke mindset is not clearly defined, it is inclusive in forms of innovative hands-on projects carried out by individuals who will, if the project works well, possibly develop it into a full-time activity. It carries ideologies of empowerment through learning and doing, social change, and development. When we write about makers in China, we need to include the linguistic enrichment achieved by translating the concept back. Adding a layer 
to the concept of maker, especially when doing fieldwork in China, can lead to misunderstandings as using chuangke can be interpreted as entrepreneur by some, businesswomen/men by others and maker by those who are part of the maker culture. As explained earlier, in Chinese, concepts are constructions of characters which evolve and can be interpreted in various ways, providing also options to manipulate, redefine and adapt to a given reality.

Adding to this, shuangchuang (双创), an abbreviation of the 'Mass Entrepreneurship and Mass Innovation' slogan, is an instrument used to spread entrepreneurship; it reunites the concepts of entrepreneurship and innovation (Renaud et al., 2017); it challenges or even contradicts the original concept of makerspace in which the autonomous and empowered individuals are placed at the centre. From a more hobbyist and freelancers' perspective, the concept evolved into early incubators, accelerators, company innovation hubs, international prototyping platforms, and businesses. On the one hand, it has altered the original definition of makerspaces, and on the other created an additional one more focused on success and economic benefits.

Translating words also means reshaping concepts and realities. It allows us to willingly, or not, incorporate additional interpretations and meanings, and also to remove the inconvenient ones. The maker culture in China was inspired to pragmatically create a new meaning adapted to its needs and ecosystem. Free time and hobbyist activities are rather new concepts in China (Huidi \& Er, 2009; Wang, 1995). Makerspaces and their communities are at the interface of hobbyism and entrepreneurship, with a serious interest in DIY and education. The marginality of the culture and its economic insecurity is a challenge for communities' sustainability and engagement. At the same time, the opportunity to try new things, with rather low stakes, is unique. The lack of Chinese political enthusiasm for makerspaces and its integration in urban narratives did not stop the natural process and ephemerality of these spaces but diversified its typology.

\section{Typologies of Places and Spaces}

The areas of interest for this research do not belong to a defined category of type of place. They are at the crossroads of places where one can work, learn, play or develop a business. Theories about third and fourth places, therefore, support the discussion and attempt to situate makerspaces, their role and opportunities.

The thirdness of space as proposed by Bhabha (1994), Soja (1996), Oldenburg (1999) widened academic discussions and the understanding of space beyond the duality of public and private spheres or home and work. It opened possibilities for self-definition, otherness, and enjoyment. The in-betweenness described by these authors corresponds to the place in which makerspaces evolve but is, at the same time, insufficient. Morisson
(2018, p. 445) goes one step further by developing a 'fourth place' theory:

In the knowledge economy, the rise of new social environments is blurring the conventional separation between the first place (home), the second place (work), and the third place. New social environments in the knowledge city can combine elements of the first and second place (coliving); of the second and third place (coworking); and of the first and third place (comingling). Furthermore, the combination of elements of the first, second, and third place in new social environments implies the emergence of a new place, the fourth place.

Makerspaces belong to Morisson's category of fourth place. The not-fully-defined concept of makerspaces reflects the position of its members and users. They are not purely different, they are parts of all three places, and at the same time allow a unique place to develop (Bolli, 2020). Makers are at the crossroads of co-living, comingling and co-working in their projects and exploration of a new lifestyle. Makerspaces are and have evolved into a fourth place with access to the Internet, the knowledge economy and circulation, and the search for new places representing alternatives to systems in place. The chronological evolution of the global maker culture with, among others, digital changes, has shaped and modified the role and place of makerspaces. They are not just the 'other place' apart from home and work, they combine elements of this first, second and third place. Passionate members mostly live, work and mingle in their makerspace as their project often becomes the priority. I observed three non-exhaustive main types of makerspaces during the research: 1) hobbyist/co-working spaces such as xinchejian and xinfab in Shanghai, 2) educational spaces such as Fablab 0 in Shanghai and Litchee Lab in Shenzhen, and 3) entrepreneurial/platformised spaces such as x.factory and SZOIL in Shenzhen (Bolli, 2020). While hobbyist/co-working makerspaces are initiated and supported by grassroots communities, educational and entrepreneurial/platformised makerspaces are supported by institutions, local governments or private companies often born from mixed initiatives. Financial and group stability are challenging to these spaces, and especially for the hobbyist/co-working types which rely on their communities.

Since the categories are intricate and permeable, they give a rather schematic understanding of the third and fourth spaces encountered in China but help define the status, priorities or intentions of the makerspaces. Each space embraces most of the different aspects in different ways. In addition to the tension created by the categorisation of the spaces, the notion of platformisation that opens places vertically for worldwide accessibility, and also fulfils the Chinese government's agenda needs to be underlined. Lin and de Kloet have investigated the emerging Chinese creative class that is part of the rapid 
platformisation of Chinese cultural production and accommodates the state's "'entrepreneurial solutionism,' while also producing digital creative entrepreneurship among Chinese 'grassroots individuals' and a dynamic digital culture permeated with contingency and negotiation" (Lin \& de Kloet, 2019, p. 2). Entrepreneurial solutionism describes the idea that developing a certain field, here entrepreneurship, is the solution for social and economic problems, moving the country closer to its dream of 'national rejuvenation' (Keane \& Chen, 2017). Digitalisation and platformisation, part of this narrative, add dimensions to the typologies of makerspaces, to the worldwide integration of people and projects, and also to the governmental priorities.

\section{Role of the Makers}

Even if often perceived as innovators for their products or projects, makers are innovators for their disruptive ways of working and developing projects, using the urban environment and ecosystem. To better understand their role, we will look at three aspects of their oftenattributed identities.

\subsection{Revolutionaries?}

Anderson's book Makers, the New Industrial Revolution, published in 2012, shed light on a culture of innovators and entrepreneurs empowered by the Internet. For China, Lindtner seems to agree that the "maker culture is envisioned as an enabler of the next industrial revolution-a source of unhindered technological innovation, a revamp of broken economies and educational systems" (Lindtner, 2015, p. 1). This teleological view serves the purpose of the maker movement ideology and reinforces it. The challenge with this type of classical narrative is that it has shaped or even been embraced by the Chinese government, deploying "resources and efforts to develop makerspaces to accelerate the cultivation of the new driving force" (State Council of PRC, 2016). Wang (2016) has a more critical approach to the matter in her article "The Makers Are Coming! China's Long Tail Revolution." The latter can also be read with some irony, as she underlines either the utopic or dystopic role of citizens on China's road to innovation. While some researchers write about making the "next industrial revolution" (Troxler, 2013, p. 181), others wonder if makers are on the 'path of post-capitalism' (Berrebi-Hoffman, Bureau, \& Lallement, 2018, p. 12), and others underline the instrumentalisation of the makers by city governments (Shea \& Gu, 2018, p. 4). If instrumentalised, are makers part of the new elite?

\subsection{Elitists?}

Depending on their results, makerspaces are places for what could be classified as tinkering, self-developed projects and innovation. Nevertheless, as mentioned ear- lier, I consider the innovation to be in the renewal of workspaces and organisation, in the freedom taken to follow a personal idea or project and with a government both attentive and reactive to their emergence but not especially to the products which could be marketed. The Chinese government aimed to create new spaces for new types of economic activities to emerge and be ready to launch experimental initiatives for it. Urban policy experimentations through pilot projects are part of the Chinese urban planning tradition (Heilmann, 2008) and the non-renewal of such an initiative is not surprising. The co-optation of the makers has not led to any major revolution or change in the economy or society on a large scale but has changed the lifepaths of those joining the communities.

In general, the non-hierarchical position of these spaces allows each member to remain independent, while at the same time being part of an infrastructure where they can contribute to its development and learn from and be inspired by others. This maker spirit of accessibility to everyone whether skilled or unskilled is not always applicable. Writing about makerspaces in the USA, Davies explains that the community has a sense of "being an elite subculture" (Davies, 2017, p. 146). The access to makerspaces for the wider population can be limited due to the stratification of the population in terms of information, knowledge, interest, time and income. Progressing to the next level shows that even a smaller portion of the already knowledgeable makers will be able to create more and better projects as Shea and Gu write criticising the idea of egalitarianism in the Shenzhen maker culture (Shea \& Gu, 2018, p. 86). This elitism creates a form of marginality of the movement, but this selectivity is not entirely restrictive. All kinds of profiles can be found in makerspaces, even if the majority are engineers, designers or technology savvy.

Understanding both the openness and limitedness of makerspaces in terms of accessibility does not change the path and lifestyle of the makers. Such individuals are on a liminal path of self-development, social change and national transformation. They are part of a marginal, ephemeral and liminal culture or group that has a potential positive impact for themselves, their surroundings, society or even further the country. As Wang mentions, the Chinese government has not been blind to this: "Whether we are speaking of maker entrepreneurs or makers as change-making citizens, it is obvious that the government has discovered the value of the individual, creative expression and grassroots energy in transforming Chinese economy and society" (Wang, 2016, p. 59).

In its 2015 political strategies, the Chinese government recognised the need of individuals, such as makers, to create a new form of entrepreneur-elite (Marshall \& Rossi, 2017; Wang, 2016; Yu \& Deng, 2015). Makerspaces are terrains of opportunities which were supported or even instrumentalised by the Chinese government and seem to be a place for a new techno-entrepreneurial elite (Hoffman, 2010). Nevertheless, even if the people 
who are part of the maker culture in China are welleducated, young and ambitious, it does not limit them and their lifepaths to the government's influence.

In general, makerspaces are liminal places and spaces institutionalised and legitimised through ritual moments and rites (Bourdieu, 1982, p. 58), where people work on their skills or their lives before taking the next step. Also, makers do not describe themselves as makers but mostly by their skills/profession (engineer, designer, etc.) or projects (urban gardener, teacher). Fieldwork shows that they are part of a narrative that they are often not aware of, but are part of the dynamic of change (Bolli, 2020). The etic and emic viewpoints are in tension. Called makers from an etic perspective, they define themselves, from an emic perspective, as engineers, freelancers, designers, students, artists, or curious persons that found a place where they could work or create their projects and share time and space without thinking of the wider ideal. Their impact is therefore double, through their projects and the surrounding narratives.

\subsection{Change-Makers}

Makerspaces in China have a transitive function and an ephemeral existence. In the urban structure built by transportation functions and buildings, which can change (but not as fast as what exists intra muros), makerspaces are particularly dynamic elements which can evolve from one day to the next due to changes in the community, lack of funding or the need to move to a new place. The imaginary which surrounds these spaces and their urban concentration is important. A city can be observed for its physical existence (roads, buildings, etc.), its life (events, etc.), its people (citizens, migrant workers, travellers, politicians, dreamers, etc.) and its dynamics (changes, migration, openings/closings). These liminal spaces of making are an urban phenomenon taking place at the crossroads of these mentioned elements. The interest in makerspaces changes over time as individuals and groups of people transit through them, and politics and governmental initiatives evolve. With rapid urban changes and, therefore, a context on the move, people are keener to go through their own transitions. According to Berrebi-Hoffman et al. (2018), makerspaces are vectors of innovation despite their possible discrete existence. They are at the origin of a cultural movement in the USA and Europe, of transformation and experimenting with new forms of fabrication linked to the access to tools and knowledge (Berrebi-Hoffman et al., 2018, pp. 18-20).

The impact of the makerspaces is in the lifepaths of its participants. They are social innovators and changemakers experimenting with ideas and work styles. The strength and impact of makerspaces currently lie in their marginality and set a blueprint for the future. According to John, the legal representative of xinchejian in Shanghai:
The makerspaces for now almost disappeared because of the rush towards subsidy [linked to the 2015 governmental initiative], these spaces are not profitable so people rush to the next place/trend. In the future, there will be more acceptance for alternative spaces....The real movement is in the future when people think they need this community to support.

Like many others who are part of the maker culture, John has 'hacked his life' and sees an opportunity for systems and lifestyles to change. The autonomy of makerspaces is purposefully generated and enables people to choose what to learn, how and when, and is integrated into a global open digital context.

\section{The Unlimitedness of Space for Urban Social Innovators}

From grassroots to co-opted, to hybrid spaces, the maker culture keeps evolving and adapting to opportunities encountered by urban social innovators. The very dynamic Chinese urban settings accelerate the success and failures of initiatives. Through digitalisation and platformisation of places, makers are not only experimenting in their urban environments, they are also sharing this environment with grassroots partnerships.

\subsection{Chinese Urban Narratives}

The Chinese urban fabric is a fertile ground for experimentation. National and international dynamics meet in the mega-cities of Shanghai and Shenzhen with the Chinese, those Chinese who have lived abroad, and foreigners. In China, the top-down approach seems to dominate, but the actual dynamics are a game between topdown frameworks and bottom-up initiatives and stakeholders finding ways to profit from the existing frameworks (Renaud, Fernandez, Puel, \& Feng, 2019; Zielke \& Waibel, 2015). In the case of the makerspaces, they have been appearing in China since 2010 and have had to negotiate their position and existence in each city. The story of the makerspaces in China is part of the period in which the country's narratives shift from 'made in China' to 'make' or 'created in China,' and 'innovated in China' (Keane, 2006; Wei, Xie, \& Zhang, 2017). While the Chinese government was focusing on innovation and creative clusters, and therefore opening opportunities for makerspaces to exist, the latter were being incubated in the cities. Makerspaces can be part of creative clusters (Wen, 2017). They have inserted themselves into the urban fabric of each city in many different ways and places and have found niches that have enabled them to be recognised. The top-down initiative of the government reached out to the municipalities and cities, which implemented it depending on their local infrastructure and interpretation. Each city developed local strategies and adapted top-down initiatives uniquely. Shanghai, where the first makerspace in China opened, 
has remained more hobbyist while Shenzhen has become a more professional and platformised maker culture linked to the city's export and fast-production history. Shenzhen's identity is now linked to creativity and innovation (O'Donnell, Wong, \& Bach, 2017).

Makerspaces are part of the intensity of the urban fabric in China. They may be ephemeral and marginal, but their networks are international and can create many dynamics and new projects on local, national, and international levels. The emergence of platformised makerspaces, especially in Shenzhen, has also given additional dimensions to the culture, which is opening the city and fluidifying personal networks. Through the accessibility through the Internet, makers worldwide are benefitting from knowledge exchange and new partnerships to develop their own projects. In Shenzhen, this is made visible by several events. The maker fair, recognised internationally, which has taken place since 2012 and is organised by chaihuo and now x.factory is also one of them. It attracts visitors from all over the world who are fascinated by this 'new Silicon Valley' (Lindtner, 2015, p. 858) and the opportunity to learn and potentially later work with local entities accessible through the hybrid makerspaces. This event is organised by grassroots makerspaces backed by a private company and supported by the local government. Another example is the International Maker Cooperation Summit and Forum which took place in 2017 and 2018, and to which Ethiopian speakers who are connected to the initiative Designed in Ethiopia (Xie, 2017, 2018) were invited. These Summit and Forum, organized by SZOIL, an entrepreneurial/platformised makerspace, took place in the framework of the National mass entrepreneurship and innovation week in Shenzhen. In this specific case, the project was initiated by a maker who sought for SZOIL partnership. The co-optation dynamic is bottom-up and is part of a strategy of outreach, recognition and financial support (Bolli, 2020).

\subsection{Global Connections}

Maker communities create new types of collaborations to implement their visions, and China has supported makerspaces also to implement a new vision which has hybridised their essence. This combination has created a unique image. Different countries are looking at China, and more specifically Shenzhen, as a model of innovation, economic renewal, and industrial production. Shenzhen's re-branding from a 'made in China' to a 'make in China' label is internationally recognised. The Chinese maker chuangke has an imprint on global maker projects linked to local Chinese makerspaces through partnerships and cooperation. Projects like Designed in Ethiopia and Kabakoo Academies partner in different ways with Shenzhen-platformised makerspaces. The enriched re-translated definition of maker corresponds to the change-making impactful makers of these projects in Addis Ababa and Bamako.
The interest of Ethiopian entities (makers, government, etc.) in such knowledge exchange is an example of the outreach of Chinese technologies and ideologies through innovation communities based in Shenzhen. Organisations like SZOIL and x.factory have benefited from the Chinese national interest in projects involving multidisciplinary exchanges, open innovation, and possible entrepreneurship. Experimental initiatives such as Designed in Ethiopia are the seeds for new dynamics between grassroots and governmental cooperation. This project, initially launched by an Ethiopian student in China in cooperation with iCog Labs in Addis Ababa, the SZOIL in Shenzhen and later the Ministry of Science and Technology of Ethiopia, has reached Ethiopian enterprises, universities, and governmental entities awakening interest, participation and support. The local communities involved have been proactive and have attracted the attention of the Ethiopian government, which started supporting and partly co-opted this grassroots initiative officially launched in March 2018. From 1,200 projects submitted by Ethiopian students, 100 were selected and invited to intensive training sessions led by Shenzhen-based experts who had been invited to Addis Ababa. After the training was completed, 5 projects were chosen. At the moment, these projects undergo patent applications, and the winners should be sent to Shenzhen for prototyping and to learn from the Shenzhen maker-entrepreneurial environment. The strength and uniqueness of this project lie in the potential of empowering youth in Ethiopia locally, by opening up to learning from others, here the maker environment in Shenzhen. One of the future goals is also to switch from a 'designed in Ethiopia' and 'made in China,' to a 'designed in Ethiopia' and 'make/made in Ethiopia' label.

Another project linking makers in Africa and China is Kabakoo Academies. It is a unique project led by local makers in Mali and other locations where individuals can learn new skills, prototype and manufacture on a small scale. Kabakoo collaborates with organisations such as $x$.factory through knowledge exchange by mentoring and distance education, through specific projects such as West Africa's first citizen platform monitoring ambient air pollution to which Seeed Studio (of which $x$. factory is part of) provided part of the materials. This cooperation is mutually beneficial as Kabakoo participants learn from Shenzhen-based organisations and receive some material, and Shenzhen-based organisations get direct feedback on product performance in local environments.

These are strong albeit rare examples of ambitious and successful grassroots projects linking Chinese and African makers (Hailemariam, 2019; Kabakoo Academies, 2019; SZOIL, 2019). Both project launchers were students in China benefitting from educational cooperation between their countries. In this specific context, China is a source of inspiration or a partner for empowering projects. Knowledge, technologies, and discourses between China and African countries circulate in complex ways, not as unidirectional, straight-forward 
and top-down as often assumed. According to Brokaw, a contributing editor to MIT's Sloan Management Review, China has become the 'World's Innovation Role Model' (Brokaw, 2017) and an important hub for entrepreneurs and makers. Without confirming or contradicting Brokaw's thought, observing the grassroots maker interactions shows a potential of inverting trends and influencing the future through innovators.

\section{Conclusion}

The young and fairly marginal maker culture in China has diversified over time from mostly hobbyist/co-working makerspaces towards more educational and entrepreneurial places with the influence of a governmental initiative of 2015 that was not renewed. The latter supported entrepreneurship and business over self-development and tinkering. These changes are also reflected in the definitions and translations of chuangke. Fascinatingly, the governmental initiative did not replace one type of spaces with another even if it pushed towards more entrepreneurial and educational profitoriented types of makerspaces. The maker concept is appropriated and adapted to the Chinese context in multifaceted ways. Indeed, this dynamic diversified the typology by creating hybrid spaces and challenged the already existing ones. At the same time, each city interprets the national initiative in its own way, dealing with an ephemeral and marginal culture. Shanghai has remained hobbyist, while Shenzhen has expanded, and transformed the original hobbyist maker culture into a hybrid borderless platformised entrepreneurship, changing the narrative of the city nationally and globally. Top-down and bottom-up dynamics are complex, and makerspaces are at the crossroads of these grassroots and governmental tensions. New opportunities are created in these fourth places of making.

Makers are given multiple roles, they are not only thought of as fulfilling the ideology of the urban China Dream (Taylor, 2015) but also participating in the growing sharing economy (Lan, Ma, Zhu, Mangalagiu, \& Thornton, 2017), and the platformisation of the Chinese society (de Kloet, Poell, Zeng, \& Chow, 2019). Despite having been considered as revolutionaries, elite or elitists, instrumentalised by the government or companies, makers-who do not describe themselves as such-are, on a human scale, change-makers. They do not fulfil agendas of saving or changing an economy, but allow individuals to gain new skills, change lifepaths and rethink ways of working and living. Makerspaces are liminal. The urban settings are the ground for projects to start, while the Internet is the key to learn, exchange, and find partners or supporters. As China is moving towards becoming an innovative power, especially in the realm of digital technologies, cities are experimenting with innovative initiatives and platformisation tools. Makers are innovators who are part of marginal, ephemeral, and liminal maker communities adapting to their environment.
They play the game of defining or re-defining what makers are and do.

The Chinese maker chuangke has an imprint on global maker projects linking makerspaces beyond places and borders. Cities are enablers of makerspaces and maker communities; they are not limiting them. As the maker culture seems to fade in China, the marginal culture sparkles with small-scale impact through projects across the world. Makerspaces represent an opportunity for ambitious and well-connected individuals and are perceived by some as blueprints for the future. Wang's (2016) definition is even more deeply experienced in projects such as Designed in Ethiopia and Kabakoo Academies with the need to transform countries' society and economy. These projects target, and are accessible to, motivated and proactive individuals, namely innovators, offering new opportunities to grow. As discussed in this article, makers are rather marginal for their rarity but directly impact personal lives, and indirectly the Chinese urban narratives, and the perception of China to shift their image from a world manufacturer with the label 'made in China,' to a nation of innovation with the motto 'designed and created in China.' This research gives a voice to makers in urban China, from behind the 'social constructions of innovations' (Pel \& Kemp, 2020), embarked on a journey negotiating their narratives and opportunities between topdown and bottom-up dynamics.

\section{Acknowledgments}

This research was supported by the Swiss National Science Foundation and the College of Humanities (CDH) at Ecole Polytechnique Fédérale de Lausanne EPFL, Switzerland. This article is a result of a four-year study in the framework of a PhD thesis with numerous interviews conducted in the field.

\section{Conflict of Interests}

The author declares no conflict of interests.

\section{References}

Akrich, M., Callon, M., Latour, B., \& Monaghan, A. (2002). The key to success in innovation part I: The art of interessment. International Journal of Innovation Management, 6(2), 187-206. https://doi.org/10.1142/ S1363919602000550

Anderson, C. (2012). Makers: The new industrial revolution (1st ed.). New York, NY: Crown Business.

Berrebi-Hoffman, I., Bureau, M.-C., \& Lallement, M. (2018). Makers: Enquête sur les laboratoires du changement social [Makers: A study on laboratories of social change]. Paris: Seuil.

Bhabha, H. K. (1994). The location of culture (1 ed.). London and New York, NY: Routledge.

Bolli, M. (2020). Liminality, ephemerality, and marginal- 
ity with impact: Makerspaces in the Chinese urban fabric: Shanghai, Shenzhen, Beijing, and Addis Ababa (Unpublished Doctoral dissertation). EPFL Lausanne, Switzerland. https://doi.org/10.5075/epflthesis-7765

Bolli, M., Renaud, C., Bloch, A., \& Protti, E. (2020). Learning from makers. In C. Renaud, F. Graezer Bideau, \& M. Laperrouza (Eds.), Realtime: Making digital China (pp. 129-153). Lausanne: EPFL Press.

Bourdieu, P. (1982). Les rites comme actes d'institution [Rites of institution]. Actes de la Recherche en Sciences Sociales, 43, 58-63.

Brokaw, L. (2017, May 10). Why China is the world's innovation role model. MIT Sloan Management Review. Retrieved from https://sloanreview.mit.edu/article/ why-china-is-the-worlds-innovation-role-model

China has ranked first worldwide in terms of incubators and makerspaces. (2017, September 19). GBTimes Bringing China Closer. Retrieved from https:// gbtimes.com/china-has-most-incubators-makerspaces-in-the-world

Davies, S. R. (2017). Hackerspaces: Making the maker movement. Cambridge and Malden, MA: Polity Press.

Day, A. (2016). DIY utopia: Cultural imagination and the remaking of the possible. Lanham, MD: Lexington Books.

de Kloet, J., Poell, T., Zeng, G., \& Chow, Y. F. (2019). The platformization of Chinese Society: Infrastructure, governance, and practice. Chinese Journal of Communication, 12(3), 249-256. https://doi.org/ 10.1080/17544750.2019.1644008

Deleuze, G., \& Guattari, F. (1987). A thousand plateaus: Capitalism and schizophrenia (2nd ed., B. Massumi, Trans.). Minneapolis, MN: University of Minnesota Press.

Dougherty, D., \& Conrad, A. (2016). Free to make: How the maker movement is changing our schools, our jobs, and our minds. Berkeley, CA: North Atlantic Books.

Driessen, H., \& Jansen, W. (2013). The hard work of small talk in ethnographic fieldwork. Journal of Anthropological Research, 69(2), 249-263. https://doi.org/10.3998/jar.0521004.0069.205

Gibb, A. (Ed.). (2015). Building open source hardware: DIY manufacturing for hackers and makers. New York, NY: Addison-Wesley.

Hailemariam, N. (2019). Connecting China and Ethiopia through innovation and technology. Medium. Retrieved from https://medium.com/ $@$ @naelhailemariam

Heilmann, S. (2008). Policy experimentation in China's economic rise. Studies in Comparative International Development, 43(1), 1-26. https://doi.org/10.1007/ s12116-007-9014-4

Hoffman, L. M. (2010). Patriotic professionalism in urban China: Fostering talent. Philadelphia, PA: Temple University Press.

Holmes, D. R., \& Marcus, G. E. (2008). Collaboration to- day and the re-imagination of the classic scene of fieldwork encounter. Collaborative Anthropologies, 1(1), 81-101. https://doi.org/10.1353/cla.0.0003

Huang, A. B. (2017). The hardware hacker: Adventures in making and breaking hardware. San Francisco, CA: No Starch Press.

Huidi, M., \& Er, L. (2009). Social transformation: The value of traditional leisure culture of China revisited. World Leisure Journal, 51(1), 3-13. https://doi.org/ 10.1080/04419057.2009.9674577

Kabakoo Academies. (2019). Everyone deserves success. Kabakoo Academies. Retrieved from https://www. kabakoo.africa/success

Keane, M. (2006). From made in China to created in China. International Journal of Cultural Studies, 9, 285-296. https://doi.org/10.1177/1367877 906066875

Keane, M., \& Chen, Y. (2017). Entrepreneurial solutionism, characteristic cultural industries and the Chinese dream. International Journal of Cultural Policy, 25(6), 1-13. https://doi.org/10.1080/10286632. 2017.1374382

Kingsley, J., \& Saunders, T. (2016). Makerspaces and the search for mass innovation. London: Nesta. Retrieved from https://media.nesta.org.uk/documents/made_ in_china-_makerspaces_report.pdf

Lallement, M. (2015). L'âge du faire hacking, travail, anarchie [The age of doing: Hacking, work, anarchy]. Paris: Seuil.

Lan, J., Ma, Y., Zhu, D., Mangalagiu, D., \& Thornton, T. F. (2017). Enabling value co-creation in the sharing economy: The case of mobike. Sustainability, 9(9). https://doi.org/10.3390/su9091504

Lin, J., \& de Kloet, J. (2019). Platformization of the unlikely creative class: Kuaishou and Chinese digital cultural production. Social Media + Society, 5(4). https://doi.org/10.1177/2056305119883430

Lindtner, S. (2015). Hacking with Chinese characteristics: The promises of the maker movement against China's manufacturing culture. Science, Technology \& Human Values, 40(5), 1-26. https://doi.org/10.1177/ 0162243915590861

Lindtner, S., Hertz, G., \& Dourish, P. (2014). Emerging sites of $\mathrm{HCl}$ innovation: Hackerspaces, hardware startups and incubators. New York, NY: ACM.

Lindtner, S., \& Li, D. (2012). Created in China: The makings of China's hackerspace community. ACM Interactions Journal, 19(6), 19-22. https://doi.org/10.1145/ 2377783.2377789

Ma, D. (2015, June 29). How makerspaces are nurturing the next wave of Chinese innovators. China Daily. Retrieved from https://www.chinadaily.com.cn/china/ 2015-06/29/content_21127750_2.htm

Marshall, J., \& Rossi, C. (2017). Making with China. Digital Culture \& Society, 3(1). https://doi.org/10.14361/ dcs-2017-0108

Morisson, A. (2018). A typology of places in the knowledge economy: Towards the fourth place. Cham: Springer. 
O'Donnell, M. A., Wong, W., \& Bach, J. (2017). Learning from Shenzhen: China's Post-Mao experiment from special zone to model city. Chicago, IL: University of Chicago Press.

Oldenburg, R. (1999). The great good place: Cafes, coffee shops, bookstores, bars, hair salons, and other hangouts at the heart of a community (3rd ed.). Berkeley, CA: Da Capo Press.

Pel, B., \& Kemp, R. (2020). Between innovation and restoration: Towards a critical-historicizing understanding of social innovation niches. Technology Analysis \& Strategic Management, 33(3), 1-13. https://doi.org/10.1080/09537325.2020.1750588

Pink, S. (2015). Doing sensory ethnography. London and New York, NY: SAGE.

Renaud, C., Fernandez, V., Puel, G., \& Feng, Z. (2019). Urban modes of assemblage: The changing spaces of innovation in Shanghai. Management International, 23(3). https://doi.org/10.7202/1062214ar

Renaud, C., Graezer Bideau, F., Bolli, M., \& Laperrouza, M. (2017). Integrating alternatives: Maker movements in China. Paper presented at the Conference "Norms and alternatives: Anthropological approaches to practices and narratives of change," Neuchâtel, Switzerland.

Sennett, R. (2009). The craftsman. New Haven, CT: Yale University Press.

Shea, P., \& Gu, X. (2018). Makerspaces and urban ideology: The institutional shaping of Fab Labs in China and Northern Ireland. The Journal of Peer Production, 12, 78-91.

Shenzhen Open Innovation Lab. (2019). Designed in Ethiopia. SZOIL. Retrieved from https://www.szoil. org/designed-in-ethiopia

Shorthose, J. (2004). A more critical view of the creative industries: Production, consumption and resistance. Capital and Class, 28(3), 1-10.

Smith, A. G. (2017). Social innovation, democracy and makerspaces (SSRN Scholarly Paper No. ID 2986245). Retrieved from https://papers.ssrn.com/abstract= 2986245

Soja, E. S. (1996). Thirdspace: Journeys to Los Angeles and other real-and-imagined places. Oxford: Blackwell Publishing.

State Council of PRC. (2016, February 4). China to create more innovation bases. State Council of PRC. Retrieved from http://english.gov.cn/premier/news/ 2016/02/04/content_281475284209241.htm

Taylor, J. R. (2015). The China dream is an urban dream: Assessing the CPC's national new-type urbanization plan. Journal of Chinese Political Science, 20(2), 107-120. https://doi.org/10.1007/s11366-0159341-7

Troxler, P. (2013). Making the third industrial revolution: The struggle for polycentric structures and a new peer-production commons in the FabLab community. In J. Walter-Herrmann \& C. Büching (Eds.), Fab lab: Of machines, makers and inventors, cultural and media studies (pp. 181-194). Bielefeld: Verlag.

Troxler, P., \& maxigas. (2014). Editorial note: We now have the means of production, but where is my revolution? Journal of Peer Production, 5.

Wang, J. (2016). The makers are coming! China's long tail. In M. Keane (Ed.), Handbook of cultural and creative industries in China (Vol. 1, pp. 43-63). Cheltenham: Edward Elgar Publishing.

Wang, S. (1995). The politics of private time: Changing leisure patterns in urban China. In D. Davis (Ed.), Urban spaces in contemporary China: The potential for autonomy and community in post-Mao China (pp. 149-172). Cambridge: Cambridge University Press.

Wei, S.-J., Xie, Z., \& Zhang, X. (2017). From 'Made in China' to 'innovated in China': Necessity, prospect, and challenges. The Journal of Economic Perspectives, 31(1), 49-70.

Wen, W. (2017). Making in China: Is maker culture changing China's creative landscape? International Journal of Cultural Studies, 20(4), 343-360.

Xie, V. (2017, October 25). Belt and road summit for international maker cooperation. Medium. Retrieved from https://medium.com/szoil/belt-androad-summit-for-international-maker-cooperationf45267d9bce5

Xie, V. (2018, November 29). Belt and road international maker forum: SZOIL. Medium. Retrieved from https://medium.com/szoil/belt-and-roadinternational-maker-forum-7b115bd5eba3

Xue, Y. (2018, November 8). Made in China: The boom and bust of makerspaces. Sixth Tone. Retrieved from https\%3A\%2F\%2Fwww.sixthtone.com\%2Fnews\% 2F1003171\%2Fmade-in-china-the-boom-and-bustof-makerspaces

Yu, J., \& Deng, W. (2015, March 19). Makers liked by the Prime Minister. People's Daily. Retrieved from http://politics.people.com.cn/n/2015/0319/c100126715378.html

Zielke, P., \& Waibel, M. (2015). Creative spaces and the local state in China: The case of Guangzhou's Redtory Art + Design Factory. City, Culture and Society, 6(2), 27-35. https://doi.org/10.1016/j.ccs.2015.03.005

\section{About the Author}

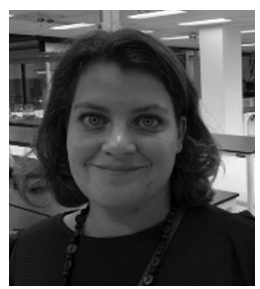

Monique Bolli is a Social Anthropologist who obtained her PhD from the EPFL College of Humanities. Her thesis focuses on innovation communities in urban China. Monique's multidisciplinary research comprised academic scholarships at the New York University Shanghai and the Curtin University in Australia. Before joining EPFL, she worked in the field of international cooperation on policy dialogue for poverty reduction and trilateral cooperation in China. 